\title{
Early doxorubicin cardiotoxicity in Malawian children admitted to Queen Elizabeth Central Hospital, Malawi.
}

\author{
Dominic Moyo ${ }^{1}$, Yamikani Chimalizeni ${ }^{1}$, Clifford Banda ${ }^{1}$, George Chagaluka ${ }^{1}$, and \\ Elizabeth Molyneux ${ }^{2}$ \\ ${ }^{1}$ Queen Elizabeth Central Hospital \\ ${ }^{2}$ College of Medicine, University of Malawi
}

September 24, 2020

\begin{abstract}
Abstract: Background. Doxorubicin chemotherapy drug, use is limited by it's potential to cause cardiotoxicity. In resource poor settings, like Malawi, monitoring of doxorubicin cardiotoxicity is not routinely conducted in cancer patients and the incidence of doxorubicin cardiotoxicity is not known. Methods. Children aged 3 months to 18 years with cancer were prospectively enrolled from the paediatric oncology ward and followed up from January 2016 to June 2019. Transthoracic echocardiographic monitoring of left ventricular ejection fraction (LVEF) was done at baseline, one month, six months and a year after completion of therapy. Cardiotoxicity was defined as a decline in LVEF of [?]10\% to a final value of $<50 \%$, and an overall incidence risk of developing cardiotoxicity was estimated. A one-way analysis of variance was conducted to compare baseline LVEF with that measured during follow up intervals. Findings. A total of 91 children were enrolled into the study, 74\% (68/91) were male, and $67 \%(62 / 91)$ were aged 5 months to 14 years. Burkitt lymphoma was diagnosed in $41 \%$ (38/91) of the children. No one experienced cardiotoxicity during the study period. However, of 77 children who had at least one follow up, five children $6 \cdot 54 \%$ (95\% CI: 2.1-14.5) experienced a reduction in LVEF of $>10 \%$, though not to a final value of $<50 \%$. No deterioration of systolic function was found among 20 children who had completed follow up. $(\mathrm{F}=2 \cdot 43$, p-value=0.07). Interpretation. In this cohort, there were no observed cardiotoxic events associated with doxorubicin administration as per pre-defined criterion
\end{abstract}

\section{Hosted file}

Early doxorubicin cardiotoxicity manuscript DM_23-09-2020.pdf available at https://authorea. com/users/361446/articles/482864-early-doxorubicin-cardiotoxicity-in-malawian-childrenadmitted-to-queen-elizabeth-central-hospital-malawi

\section{Hosted file}

TABLE doc DM_18_09_2020.pdf available at https://authorea.com/users/361446/articles/482864early-doxorubicin-cardiotoxicity-in-malawian-children-admitted-to-queen-elizabethcentral-hospital-malawi

\section{Hosted file}

TABLE 2 doc_DM_18_09_2020.pdf available at https://authorea.com/users/361446/articles/482864early-doxorubicin-cardiotoxicity-in-malawian-children-admitted-to-queen-elizabethcentral-hospital-malawi

\section{Hosted file}

TABLE 3 Doc_DM_18_09_2020.pdf available at https://authorea.com/users/361446/articles/ 482864-early-doxorubicin-cardiotoxicity-in-malawian-children-admitted-to-queen- 
FIGURE 1 The study flow diagram.

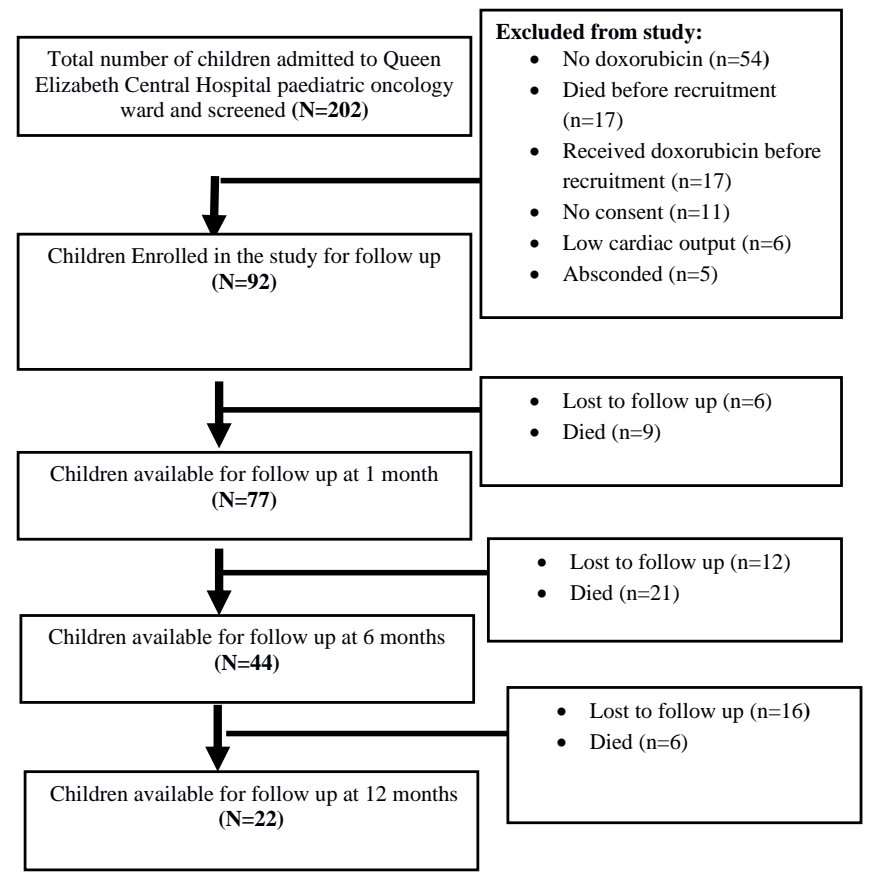

